\title{
On Self-learning Ability of College Students and Its Cultivation
}

\author{
Jiaming Zhong, Jisheng He *, Zhijuan Liu * \\ Xiangnan College, Chenzhou, Hunan \\ hulixue22@163.com
}

Keywords: University and college students; Self-learning ability; Cultivation

\begin{abstract}
Self-learning ability is the key of college students' effective learning. To develop the college students' self-learning ability, it should be based on the connotation and structure of self-learning ability, starting from cultivating the self-directed, self-monitoring, self-regulation and self-evaluation ability of them, complying with the knowledge, skills and abilities relationships, and in accordance with self-learning ability theoretical basis as well, to determine the self-learning methods and measures. The cognitive-oriented guiding measures are mainly adopted. Self-learning ability is a vital learning ability for college students, which is the key for effective learning. Since the 1990s, the world regarded the students' self-learning ability as an important educational goal, and performed studies from practice exploration to theory summary. And today many students' learning initiative is not strong and they do not know how to learn, and therefore self-learning ability of college students and their cultivation are very important.
\end{abstract}

\section{Connotation of self-learning ability}

Education experts at home and abroad define self-learning, including "process (activity) theory" (Pintrich, Zimmerman, Han Qinglin, etc.), "manner model theory" (Yu Wensen, Cheng Xiaotang, etc.), "ability theory" (Holec, etc.) and various perspectives. "Process (activity) theory": self-learning is an initiative, constructive learning process (Pintrich, 2000); self-learning is the learner's self-directed feedback cycle process, and based on these feedback to adjust their learning activities (Zimmerman, 1900); and so on. I agree with "process (activity) theory". Self-learning is a process (or activity) like the concept of "teaching". Teaching is a process (or activity). The effectiveness of teaching is related with teaching concept, teaching method, teaching ability and other factors. Self-learning is affected by the awareness, habits, skills and methods and other factors. So the cultivation of self-learning for college students is to cultivate their awareness, habits, skills and methods, in which self-learning ability is the core content.

Self-learning ability was first proposed by Holec (1981) who defined "self-learning"as" the ability to be responsible for their own learning" and this ability is reflected concretely in determining the learning goals, content and plan, choosing learning methods and strategies, monitoring learning process to assess learning effects.

Arnold (1999) pointed that the self-learning ability was consisted by psycho - social support and technical support. Psycho - social support refers to the motivation and influencing factors; technical support means cultivating learners' ability to set goals, and the ability to select materials, approach

${ }^{*}$ Corresponding author 
and finish and perform tasks, as well as the ability of self-monitor, and the ability to select the evaluation criteria and self-evaluation ability.

Little (1991) defined the self-learning as three capabilities: the ability for objective, critical reflection, the ability to make decisions and the ability to take independent action. And so on.

So, what self-learning ability? Simply speaking, that is the learning ability manifested in self-learning activities. In psychology, ability means the necessary psychological characteristics for people to complete an activity of individual, which is a necessary condition for successful completing certain tasks. Thus, self-learning ability is the sum of psychological quality that learners successfully completing the task of self-learning. Self-learning ability is not just a mental ability, but also a social ability, or the ability to survive a sustained and comprehensive development.

According to the process (activity) theory, self-learning is to illus trate the essence from the whole process of learning. Pang Weiguo believes that if students can identify learning objectives, develop learning plan and do specific learning readiness before the learning activities and also they can make self-monitoring, self-feedback and self-regulation for learning progress, learning methods in their learning activities to in learning activities, as well as making self-examination, self-summary, self-evaluation and self-recovery after learning, then his learning is self-learning [1].

According to the view above, we believe that college students self-learning ability means the sum of psychological quality that they can finish their self-learning tasks successfully, including self-directed, self-monitoring, self-regulation and self-evaluation ability. Wherein the self-directed abilities include setting goals, planning ability; self-monitoring abilities includes self-examination, will control; self-regulation includes self-feedback, self-remediation capabilities; self-evaluation abilities includes self-reflection (reflection), self-summary ability.

\section{Self-learning ability structure of college students}

Self-learning ability is based on the cognitive ability, and shows a special leaning ability in detailed subject learning activity.

Self-directed ability: the self-directed ability means the ability that students determine their detailed learning contents, set specific learning goals, develop a detailed study plan after analyzing the learning task. The so-called learning goal means the desired results that want to obtain in the learning activities. Learning goals have simulating, guiding and regulatory functions. Learning objectives are composed of a series of target groups, which include the overall learning objectives, stage objectives, curriculum goals and lesson objectives. Students can find their own learning deficiencies in the learning process and transforms them into clear learning objectives, and develop a learning plan based on learning objectives, identify specific learning content and learning time (or even place), that is a solution to "learn what, when and where to learn "problem, which is a prerequisite for self-learning. It's the only way to prevent blindness, and enhance the consciousness of learning, thereby enhancing the quality of learning. Self-directed ability is very important, and it is the primary ability of self-learning.

Self-monitoring, regulation ability: self-monitoring and self-regulatory are closely linked processes. Self-monitoring, regulation is the ability to ensure that students can achieve the desired learning objectives, and make the learning activity itself as an object of consciousness in the whole process of learning, continuing to conduct pro-active plan, inspection, evaluation, feedback, control and adjustment. This ability is the most advanced part in many components of learning activities. It 
is not only the controller of learning activities, but is the internal mechanism of self-learning ability development.

When college students are conducting self-learning without supervision and control of other people and they must monitor their own learning process, continuing to find and analyze the learning problems and reasons, and adjust their learning behavior accordingly. Therefore, self-monitoring, regulation is the key to achieve the desired goal of students' self-learning. Self-monitoring and regulation of learning is the metacognitive process directing learning process, which is also a basic component of self-learning process.

Self-evaluation ability: self-evaluation ability means the ability for college students to judge the effectiveness of their own learning based on previous performance and the results of observation and recording. The ability of college students' self-evaluation includes the students' ability of self-reflection (reflection), self-summary ability, including the evaluation of motivation, learning attitude evaluation, learning method evaluation and evaluation of learning outcomes especially. A student that is good at learning can analyze and comprehend his own progress and problems in learning completely through self-evaluation.

\section{Cultivating college students' self-learning ability}

As an important learning ability that students should have, self-learning ability is not innate, but obtained in the long-term practice of continuous learning cultivation with continuous development and improvement of students' self-awareness. It needs to be based on the experience of education, and teachers need to continue to carry out "educational intervention" (Candy, 1991). That is college students' self-learning ability forms with teacher's training and guidance.

Base on the relationship of knowledge, skills and abilities: knowledge, skills are the basis of abilities. As we know, to foster students' ability to learn, it is necessary to enable students to master the knowledge of self-learning and train their self-learning skills. According to cognitive constructivist theory, enable students to master the metacognitive knowledge and train their metacognitive skills through teaching strategies and contexts simulation.

Strategy teaching is to teach college students learning strategies to address the issues like college students' low metacognitive level, lack of strategic approach. Learning strategies can be divided into two types: one is general learning strategy that is suitable for any discipline, such as planning, managing learning time; the other is specific learning strategy used for the specific learning content, such as notes and so on. Thus teachers should teach students a variety of general and specific learning strategies as much as possible in the teaching process, especially for the freshmen. Scenarios simulation means that teachers construct certain situations to support college students activating their learning strategies and methods. That is teachers provide examples on the basis of combining teaching content, making the strategies applicable terms and conditions clear, to give college students the opportunity to practice the strategies fully, making proficient. The former is to make students master the knowledge of self-learning, and the latter is to train college students self-learning skills. On the basis of self-learning knowled ge and skills, and after repeated use in learning activities, self-learning ability naturally forms.

Some scholars believe that cultivating college students' self-learning ability should start from cognitive directional guiding measures and non-cognitive type guiding measures. The so-called non-cognitive type guiding measures means that teachers achieve the purpose of cultivating college students' self learning ability from changing their teaching ideas, creating a relaxed and equal 
learning atmosphere to stimulate college students' motivation, training students' learning responsibility and other aspects. The so-called cognitive type guiding measures means that teachers cultivate college students' self-learning ability by guiding college students to make learning objectives, plans, select learning content, methods and strategies, inspect study results, as well as adjust or correct learning objectives, plans, and strategies. Cognitive directional guiding measures include cognitive self-directed measures, which come from Vygotsky's theory of self-regulation of speech. Verbal self-regulation can foster students' self-learning ability (Manning, 1988). [2] He believes that the self-directed tips given by teachers will guide students to practice, so that students can make effective monitoring and regulation for learning, to improve self-learning ability. Of course, in cultivating students' self-learning ability, non-cognitive guiding measures are also very important, but I think this is a measure to cultivate self-learning consciousness. Although awareness of self-learning is the prerequisite for developing self-learning ability, and self-learning awareness and self-learning ability cannot be separated, they should be penetrated, constrained, but they cannot be confused. According to Pang Weiguo, the self-learning process is "willing to learn", "know how to learn", "able learn", "stick to learning" process, then cultivating self-learning issue is to solve the issue of "willing to learn"; cultivating college students' self-learning ability is to solve the issue of "know how to learn", "able to learn", "stick to learning" issue. So to cultivate self-learning ability of college students, we should determine the methods and measures based on the connotation of self-learning ability, starting from the structure of self-learning ability and following the relationship of knowledge, skills and abilities in accordance with the theoretical basis of self-learning ability. Thus to cultivate self-learning ability, we primarily use cognitive directional guidance measures. It includes the following aspects:

Guide college students making learning goals and plans, and develop their self-direction ability. Teachers guide students analyzing their needs, developing concrete and feasible learning objectives and comprehensive study plan before specific learning based on the tasks. Teachers can also develop a learning plan jointly with students. The general content of the plan includes learning content, methods selection, learning time arrangement etc. To urge students developing learning objectives, teachers may adjust the original teaching sequence appropriately in the teaching activities. For example, at the beginning of a new chapter, teachers point out the key, difficult knowledge and required background knowledge and goals, which will benefit students learn to set goals and plans. Because students can only set the learning goals that may actually stimulate internal dynamics after mastering these specific messages. Under the guidance learning objectives, it will be easy to ask students make detailed plans, and college students are willing to follow the study plan and join new learning activities actively.

Guide students to monitor the learning process, develop self-monitoring capability. Monitoring is one of the metacognitive strategies and an important self-learning skill. In self-learning process, students should always check the implementation of stage objectives, learning progress and results. Monitoring is to check the task performing results and see whether the time resource is used reasonably, as well as the progress of learning. In general, self-monitoring is needed before, during, and after learning. Teachers instruct students to guide their own learning process by the determined target and always check the implementation of their plans, goal achieving situation. Taylor (Taylor, 1984) thinks that it is also a good measure by signing "personal learning contract" with students.

In the learning process there will always be various difficulties, so it is very important to cultivate students' will overcoming learning difficulties. We believe that the training various will control 
strategies by college students' implicit and explicit self-control process to develop their self-monitoring abilities.

Instruct students to use the feedback information, take remedial measures to continuously enhance the self-regulation ability. Self-regulation is to adjust learning progress or bring the learning process away from the learning goal into normal track based on the results of self-monitoring. It includes self-feedback based on the expected learning outcomes or goals for learning and self-remedial process according to self-feedback results for the inappropriate learning steps, learning strategies, etc.

Teachers instruct students to obtain information in the course of inspection, actively look for the reasons and discover the problems, so as to adjust or modify their original learning objectives, plans, adjust or modify or even interrupt the scheduled learning strategies, procedures and so on. Learning self-monitoring and regulation is metacognitive process directed learning process, a basic component of self-learning process, so in the process of training students self-learning ability, it should be paid full attention, so that make students form metacognitive awareness, enrich metacognitive knowledge, internalize metacognitive experiences and foster metacognitive ability.

Guide students' self-reflection and summary, to improve the ability of self-evaluation. fter completing learning activities, college students' in-depth reflection and summary is the most important part to improve self-learning ability of college students. Teachers should help students review, reflect every step in self-learning process, including the initial goal setting, selecting the learning strategies to learning results attribution, summarizing the efforts and results obtained from the reflection, and accumulating experience. So that students continue to do self-reflection, self-improvement in the self-evaluation process and achieve the purpose of translating from specific learning activities to abstract experience, completing the process of external context internalizing cognitive structure of the mind, so that college students can properly evaluate themselves, to improve their self-evaluation ability.

In short, self-learning ability of college students impacts the effectiveness of their learning directly. Training students' self-learning ability should be an important task of higher education, causing the emphasizing of most higher education. The cultivation of self-learning ability should penetrate into the classroom, starting from the students' self-directed, self-monitoring, self-regulation and self-evaluation ability, prompting the development of self-learning ability of college students.

\section{Acknowledgements}

The study has obtained Hunan Province Education Science "the 12 th 5-year plan" programming research project (XJK012CGD032、XJK012BJJ002), Hunan Province 2013 Regular Institutions of Higher Education Teaching Reform Project (Xiang Jiao Tong[2013]223 -447).

\section{References}

[1] Pang Weiguo. Self-learning: Principles and Strategies of Learning and Teaching [M]. Shanghai: East China Normal University Press, 2003

[2] Manning, B.H..Cognitive Self-Instruction for Classroom Processes[M].State University of New York Press, 1991. 
[3]Knowles M.Self-directed learning:A guide for learners and teachers[M].Toronto:The Adult Education Company, 1975.18.

[4]HeJisheng.Predicament \& Countermeasures of Teaching Outlook \& Behaviou Transformation of Teachers[J]. Theory and Practice of Education,2009,29(01):42-44.

[5] Jackson,P.W.Life in classrooms.1968.

[6]Husen,T.,The International Encycolpedia of Education:Research and Studies, 1985,V01(2):300-303.

[7]HE Q iaoyan,HE Jisheng. An exploration of the conception of self-directed learning[J].JOURNAL OF HEBEI NORMAL UNIVERSITY/Educational Science Edition,2009,11(02):33-36.

[8]Jonhnson D.W,Jonhnson R.T.Cooperative earning.http://www.clcrecom/pages/cl.html,2001.

[9]Hiemstra, R..Self-directed learning.In Husen,T.\&Postlethwaite,T.N.(Eds.).The International Encyclopedia of Education (2nd ed)[Z].Oxford:Pergamon Press,1994.2.

[10]Tough,A.M..The Association Obtained by Adult Self-Teachers[J].Adult Education(USA), 1966(17):33-37.

[11]Knowles,M..Self-directed learning:A guide for learners and teachers[M].Toronto:The Adult Education Company,1975.18.

[12]Long,H.B..Resources related to overcoming resistance to self-direction in learning[A].In R.Hiemstra\&Brockett,R.(Eds.),Overcoming resistance to self-directed learning in adult learning:New Direction $\mathrm{s}$ for Adult and Continuing Education,No.64[C].San Francisco:Jossey-Bass, 1994.23.

[13]Brookfield,S..Self-directed learning:A Critical Review of Research[A].In Brookfield,S.(eds)Self-directed learning:From Theory to Practice[C].San Francisco:Jossey-Bass, 1985.19.

[14]Gibbons,M..Self-directed learning handbook:challenging adolescent students excel[M].San Francisco:Jossey-Bass,2002.2.

[15]Guglielmino,L.M..Development of the self-directed learning readiness scale.(Doctorral dissertation, university of Georgia,1977)[D]. Dissertation Abstracts International,1977,26:6467 A. 